\title{
Learning from a T-Shirt: Engaging Students with Autonomic Pharmacology to Improve Test Performance
}

\author{
Mustafa Ahmed Alshagga* \\ Associate professor (Teaching \& Learning), Department of Biomedical Sciences, University of Nottingham Malaysia Campus, JalanBorga, Semenyih, \\ Malaysia
}

Submission: April 06, 2018; Published: April 12, 2018

* Corresponding author: Mustafa Ahmed Alshagga, Associate professor (Teaching \& Learning), Department of Biomedical Sciences, University of Nottingham Malaysia Campus, JalanBorga, Semenyih, Malaysia; Email: Mustafa.al-shagga@nottingham.edu.my

Abstract

Background: Educators have encountered the problem of declining scientific knowledge in clinical practice. The multimedia principle is based on the cognitive theory of learning and posits that people tend to learn more effectively from images and text than only text. This is a pilot experimental study, aimed to explore learning about the autonomic nervous system (ANS) from t-shirts designed showing both images and words.

Method: Forty-nine first-year students from the Biomedical Sciences and Pharmaceutical Sciences, University of Nottingham Malaysia Campus (UNMC) were randomly assigned to either an experimental (EG) or control group (CG). Both groups received four ANS pharmacology lectures prior to a small-group activity. In the small-group session, an intervention was done; both groups completed a pre-test and post-test about ANS pharmacology. Both groups were given t-shirts designed as teaching material. After two weeks of wearing the t-shirts, a retention test was conducted.

Results: Both groups had a similar level of knowledge of ANS at the pre-test (EG mean $2.0 \pm 1.3$ vs CG 2.6 \pm 1.6 ), post-test (EG $3 \pm 1.2$ vs CG 2.5 \pm 1.2 ) and retention (EG $4.5 \pm 2.2$ vsCG $3.7 \pm 2.9$ ). No statistically significant difference was found in the scores between both groups. Repeatedmeasure analysis of variance (ANOVA) showed a statistically significant improvement of the mean scores, particularly at the retention test ( $\mathrm{F}=$ $14.80, \mathrm{p}<0.001)$, and a moderate effect size $(40 \%)$.

Conclusion: Long-term (but not short-term) engagement with learning t-shirts stimulatedthe visual and auditory senses and produced a significant improvement on the test scores of ANS pharmacology students. Well-designed educational research is needed to verify the findings and determine how the engagement occurred and the level of learning.

Keywords: Learning; Engagement; Autonomic pharmacology; Multimedia principle

Abbreviations: ANS: Autonomic Nervous System; UNMC: University of Nottingham Malaysia Campus; CG: Control Group; EG: Experimental; MCQs: Multiple Choice Questions; USMLE: United States Medical Licencing Examination; SD: Standard Deviation; ANOVA: Analysis of Variance

\section{Introduction}

Within last five decades, healthcare curricula have undergone major changes. The traditional (structured) curriculum, based on the 'building blocks' of separated academic courses, such as anatomy, biochemistry, or pharmacology, has shifted to an integrated curriculum where the topics of basic and clinical sciences are organised in a specific manner to be taught as a whole [1]. Content acquisition has been replaced by outcome 'competency' or knowledge application. In addition, the responsibility of content delivery has shifted from teachercentred to student-centred, where the student is responsible to direct his or her self-learning, and the learning objectives 'to understand 'and 'to describe' have been replaced by 'to show' and 'to demonstrate' [2].
Pharmacology is a core subject. It is also affected by these curricula reforms, and its teaching methods have become creative and innovative towards better integration with other basic and clinical sciences [3]. The communication skills, clinical skills, professionalism, and ethics have been embedded in the early years of health education, affecting core basic sciences, as proposed by science educators [4]. Educators haven countered the problem of declining scientific knowledge in clinical practice [5]. Healthcare learners' dissatisfaction has been documented in the literature $[6,7]$. As a teacher, I have faced the problem of the inability of the students to recall basic sciences in medical, pharmacy, and biomedical sciences, particularly the basics of autonomic nervous system (ANS). This article describes a method of teaching in 
attempt to overcome the declining ANS knowledge by prolonging the engagement of students with the core teaching material. The theory that underpins the teaching method is principally based on the cognitive multimedia principle [8]. Multimedia learning occurs when students receive information presented in more than one mode, for example written text and images or graphical illustrations. The term multimedia explains the use of multiple resources presented through multiple formats via multiple sensory (visual and auditory) modalities [9]. This study will undertake the application of this principle to explore the effect of the principle in fostering improved ANS test performance by repeated exposure tocore knowledge in ANS pharmacology in the form of text and an imageont-shirtswore by the students for a given time.

\section{Method}

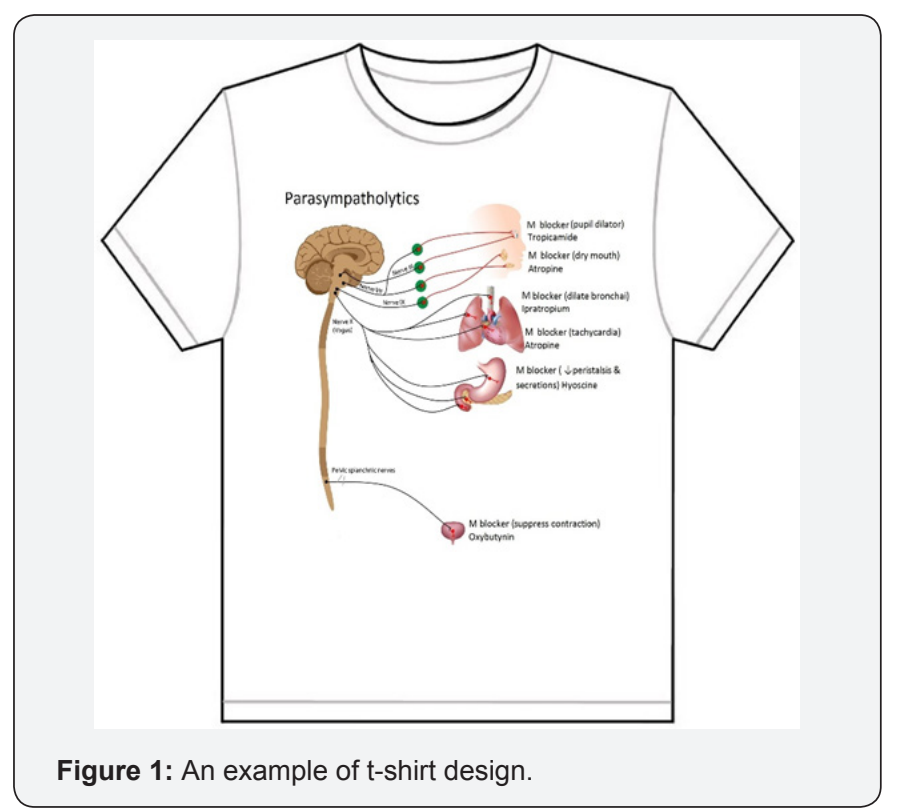

An interventional study recruited 49 Year 1 students who had attended fourlectures about the ANS. The study has been approved by the Science and Engineering Research Ethical Committee,
University of Nottingham Malaysia Campus (UNMC), and student consents were collected. Students were randomly assigned to either an experimental (EG) ( $\mathrm{n}=24)$ or control group (CG) $(\mathrm{n}=$ 25).A two-hour case study session is timetabled for the first part of this study, in which the two groups sit in two separate venues and answer a pre-test comprising 14 multiple choice questions (MCQs) about ANS. The MCQs were extracted from the United States Medical Licencing Examination (USMLE). Immediately after the pre-test, both groups are divided into four small groups of six students each, except one group with seven students in the CG. Each small group is provided with a case study comprising two scenarios about sympathetic and parasympathetic systems. Each scenario is accompanied by open-ended questions where the participants can discuss the scenario and answer the question within the small group. Designated learning aids are handed out to each group at the start of the case study. For the EG, t-shirts with printed images and words serve as al earning aid (Figure 1). The CG was given tables summarising the same information as depicted on the t-shirts (i.e., sympathetic or parasympathetic receptors, agonistic or antagonistic drugs and their corresponding effects). At the end of the two-hour case study, a post-test was administered. After the session, CG students have received similar $\mathrm{t}$-shirts exactly like the EG. These $\mathrm{t}$-shirts are given free as compensation. At least ten students have been scheduled to wear these t-shirts per day. After two weeks, a retention test was conducted; after finishing the test, a survey was given measuring the engagement of students within a small-group session and after the post-test.

\section{Statistical Analysis}

The scores of the ANS performance at the pre-test, post-test, and retention test were described by the mean plus or minusthe standard deviation (SD). An independent t-test was used to compare the EG and CG. A repeated-measure analysis using two-way analysis of variance (ANOVA) was used to analyse the performance overtime and the intervention. In all analyses, $\mathrm{p}<$ 0.05 was considered a significant effect. The analysis was done using SPSS ( $v$ 24).

\section{Results}

Table 1: Descriptive statistics of the pre-test, post-test, and retention test performance on ANS questions.

\begin{tabular}{|c|c|c|c|c|c|c|}
\hline & $\begin{array}{c}\text { Pre-test } \\
\text { (mean } \pm \text { SD) }\end{array}$ & $\begin{array}{c}\text { Independent } \\
\text { t-test } \boldsymbol{P} \text {-value }\end{array}$ & $\begin{array}{c}\text { Post-test } \\
\text { (mean } \pm \text { SD) }\end{array}$ & $\begin{array}{c}\text { Independent } \\
\text { t-test } \boldsymbol{P} \text {-value }\end{array}$ & $\begin{array}{c}\text { Retention } \\
\text { (mean } \pm \text { SD) }\end{array}$ & $\begin{array}{c}\text { Independent } \\
\mathrm{t} \text {-test } \boldsymbol{P} \text {-value }\end{array}$ \\
\hline $\begin{array}{c}\text { Experimental } \\
\text { Group (24) }\end{array}$ & $2.0 \pm 1.3$ & $\mathrm{t}=-1.2$ & $3.0 \pm 1.2$ & $\mathrm{t}=1.4$ & $4.5 \pm 2.2$ & $\mathrm{t}=0.68$ \\
\hline Control Group (25) & $2.6 \pm 1.6$ & $\mathrm{P}=0.236$ & $2.5 \pm 1.3$ & $\mathrm{P}=0.160$ & $3.7 \pm 2.9$ & 0.498 \\
\hline
\end{tabular}

The inferior performance of both groups on the test was not surprising; the causes will be explained in the limitations. Both groups, EG and CG, have a similar level of knowledge at the pretest ( $p>0.05)$, indicating there was no difference between the two groups on ANS knowledge. The post-test and retention tests were without a statistically significant difference (Table 1). There was a slight improvement in the EG on the post-test after working with the $t$ shirt for two hours, but the difference was not significant. This finding could indicate that the multimedia principle requires time to improve learning. An interesting finding to report was the improved performance after two weeks of exposure to the t-shirts for both groups, which approximately doubled their previous pre-test scores. Repeated-measure ANOVA showed a statistically significant improvement of mean scores overtime 
for three assessments $\left(F_{(1.3-39.8)}=14.8, p<0.001\right)$ (Table 2). As the $t$-shirts were distributed to both groups, the effect of the intervention between the two groups was not significant. There was no interaction over time. Self-reported student engagement with the learning aid was greater in the EG compared to the CG $(\mathrm{p}=0.03)$.

Table 2: Repeated measures analysis 2-way ANOVA showing the effect of the intervention and time over students' performance in ANS test.

\begin{tabular}{|c|c|c|c|c|c|c|}
\hline Source & MS & df & SS & $\boldsymbol{F}$ & $\boldsymbol{P}$-value & ES \\
\hline Performance over time & 93.9 & 1.4 & 133.04 & 14.80 & 0.001 & 0.40 \\
\hline Intervention (EGvs CG) & 0.34 & 1 & 0.34 & 0.12 & 0.733 & 0.005 \\
\hline Interaction Time X Intervention & 4.82 & 2 & 8.34 & 1.51 & 0.234 & 0.062 \\
\hline Error & 3.19 & 39.8 & 127.3 & & & \\
\hline
\end{tabular}

$\mathrm{MS}=$ Mean Square, $\mathrm{df}=$ degree of freedom, $\mathrm{SS}=$ sum square, $\mathrm{F}=$ ratio, $\mathrm{ES}=$ effect size (partial Eta square)

\section{Discussion}

According to the Ebbinghaus curve 'the curve of forgetting', students are expected to memorise about $25 \%$ of the taught material after six days of class [10]. Custers(2010) review also reports for getting basic science knowledge as a real problem facing healthcare education and that the decline of knowledge is probably due to non-use of information overtime [10]. Therefore, the inferior performance in this study could be attributed to the time after the last lecture (8 days) without the retrieval of the knowledge. Nevertheless, the USMLE test questions are used for international accreditation for medical students who have finished the basic sciences. Our students are biomedical science students in their first semester who have not yet finished all the basic sciences. The findings of the study showed that the multimedia principle improves student performance on ANS content. The multimedia principle could obviously explain learning improvement through two-way channels (visual and auditory). The results have not shown significant improvement of learning over a brief time $(2$ hours), but repeated exposure to the core knowledge depicted on thet-shirts allowed a remarkable improvement overtime after two weeks. These results are consistent with a study that reported a short period intervention [11] and a long duration of three months [12].

The study represented a pilot project to explore an innovative method of teaching ANS pharmacology. The findings were very encouraging to further improve the study design and the effect on learning. There are limitations, such as the absence of a real controlled experimental study, the design of the t-shirts, and the small font size, making it hard to see from a distance. In addition, there was no qualitative part to explore in depth how learning was improved and the effect of the motivation to study after exposure to challenging MCQs. The study did not measure the recall and application as separate qualities of learning. However, the findings of this study call educator attention to the effect of engagement and the improvement in designing learning materials and how this could improve student engagement with learning and could subsequently improve academic performance in general.

\section{Conclusion}

Long-term engagement (but not short-term engagement) with learning t-shirts stimulates visual and auditory senses and produced a significant improvement on the test scores of ANS pharmacology students. Well-designed educational research is needed to verify the findings and determine how the engagement occurred and the level of learning.

\section{Acknowledgement}

The author is thankful for colleagues (Dr Ibrahim Abdul Aziz Al-Jurishi, Dr Aini Hamid, Prof. Dr Ting Kang Nee) who supported and organised the activities and thanks for Biomedical and pharmaceutical sciences students who helped in accomplishment of this study. Thanks for Alawi Mustafa who key in the data.

\section{References}

1. Frank JR (1980) Competency-based education.

2. Frank JR (2010) Competency-based medical education: theory to practice. Medical teacher 32(8): 638-645.

3. Lim AG, M Honey (2006) Integrated undergraduate nursing curriculum for pharmacology. Nurse Education in Practice 6(3): 163-168.

4. Hopkins R (2015) Integrating basic science without integrating basic scientists: reconsidering the place of individual teachers in curriculum reform. Acad Med 90(2): 149-53.

5. Kerfoot BP, Brotschi E (2009) Online spaced education to teach urology to medical students: a multi-institutional randomized trial. Am J Surg 197(1): 89-95.

6. King RL (2004) Nurses' perceptions of their pharmacology educational needs. Journal of advanced nursing 45(4): 392-400.

7. Gupta S (2014) The attitudes and perceptions of medical students towards basic science subjects during their clinical years: A crosssectional survey. Int J Appl Basic Med Res 4(1): 16-9.

8. Mayer RE (1995) A generative theory of textbook design: Using annotated illustrations to foster meaningful learning of science text. Educational Technology Research and Development 43(1): 31-41.

9. Mayer RE (2002) Multimedia learning. Psychology of learning and motivation, Elsevier 41: 85-139.

10. Custers EJ (2010) Long-term retention of basic science knowledge: a review study. Advances in Health Sciences Education 15(1): 109-128.

11. Davenport J, Klahr D, Koedinger K (2007) The influence of molecular diagrams on chemistry learning. Research on Learning and Instruction, p. 1-4.

12. Issa N (2011) Applying multimedia design principles enhances learning in medical education. Medical education 45(8): 818-826. 
(C) This work is licensed under Creative cC) Commons Attribution 4.0 License BY DOI: 10.19080/JOJNHC.2018.07.555709

\section{Your next submission with Juniper Publishers} will reach you the below assets

- Quality Editorial service

- Swift Peer Review

- Reprints availability

- E-prints Service

- Manuscript Podcast for convenient understanding

- Global attainment for your research

- Manuscript accessibility in different formats

( Pdf, E-pub, Full Text, Audio)

- Unceasing customer service

Track the below URL for one-step submission https://juniperpublishers.com/online-submission.php 